\title{
Fetal and Maternal Absorbed Dose Estimates for Positron-Emitting Molecular Imaging Probes
}

\author{
Tianwu Xie ${ }^{1}$ and Habib Zaidi ${ }^{1-3}$ \\ ${ }^{I}$ Division of Nuclear Medicine and Molecular Imaging, Geneva University Hospital, Geneva, Switzerland; ${ }^{2}$ Geneva Neuroscience \\ Center, Geneva University, Geneva, Switzerland; and ${ }^{3}$ Department of Nuclear Medicine and Molecular Imaging, University of \\ Groningen, University Medical Center Groningen, Groningen, The Netherlands
}

PET and hybrid (PET/CT and PET/MR) imaging currently play a pivotal role in clinical diagnosis, staging and restaging, treatment, and surveillance of several diseases. As such, limiting the radiation exposure of special patients, such as pregnant women, from PET procedures is an important challenge that needs to be appropriately addressed because of the high sensitivity of the developing embryo/ fetus to ionizing radiation. Therefore, accurate radiation dose calculation for the embryo/fetus and pregnant patient from common positron-emitting radiotracers is highly desired. Methods: To obtain representative estimates of radiation dose to the human body, realistic biologic and physical models should be used. In this work, we evaluate the $S$ values of 9 positron-emitting radionuclides $\left({ }^{11} \mathrm{C}\right.$, ${ }^{13} \mathrm{~N},{ }^{15} \mathrm{O},{ }^{18} \mathrm{~F},{ }^{64} \mathrm{Cu},{ }^{68} \mathrm{Ga},{ }^{82} \mathrm{Rb},{ }^{86} \mathrm{Y}$, and $\left.{ }^{124} \mathrm{I}\right)$ and the absorbed and effective doses for 21 positron-emitting labeled radiotracers using realistic anthropomorphic computational phantoms of early pregnancy and at 3-, 6-, and 9-mo of gestation and the most recent biokinetic data available. The Monte Carlo N-Particle eXtended general-purpose Monte Carlo code was used for radiation transport simulation. Results: The absorbed dose to the pregnant model is less influenced by the gestation for most organs or tissues, but the anatomic changes of the maternal body increases the effective dose for some radiotracers. For ${ }^{18} \mathrm{~F}-\mathrm{FDG}$, the estimated absorbed doses to the embryo/fetus are 3.05E-02, 2.27E-02, 1.50E-02, and 1.33E-02 mGy/MBq at early pregnancy and 3-, 6-, and 9-mo gestation, respectively. The absorbed dose is nonuniformly distributed in the fetus and would be 1.03-2 times higher in the fetal brain than in other fetal soft tissues. Conclusion: The generated $S$ values can be exploited to estimate the radiation dose delivered to pregnant patients and the embryo/fetus from various PET radiotracers used in clinical and research settings. The generated dosimetric database of radiotracers using new-generation computational models can be used for the assessment of radiation risks to pregnant women and the embryo/fetus undergoing PET/CT imaging procedures. This work also contributes to a better understanding of the absorbed dose distribution in the fetus.

Key Words: PET; pregnant female model; radiation dosimetry; Monte Carlo; simulation

J Nucl Med 2014; 55:1459-1466

DOI: 10.2967/jnumed.114.141309

Received Apr. 7, 2014; revision accepted Jun. 20, 2014.

For correspondence or reprints contact: Habib Zaidi, Geneva University Hospital, Division of Nuclear Medicine and Molecular Imaging, $\mathrm{CH}-1211$ Geneva, Switzerland.

E-mail: habib.zaidi@hcuge.ch

Published online Jul. 14, 2014

COPYRIGHT (c) 2014 by the Society of Nuclear Medicine and Molecular Imaging, Inc.
O reported as the second most common cause of death during reproductive years in the United States (1). PET is playing an increasingly important role in the diagnosis, staging, and monitoring of response to treatment in a variety of cancers (2). It uses positron-emitting labeled tracers to visualize in vivo biochemical processes and molecular events in the human body, thus allowing the detection and characterization of disease in its earliest stages. As such, molecular PET imaging provides valuable diagnostic information that may not be easily obtained using conventional imaging techniques (3). The diagnosis of cancer during pregnancy is a relatively rare phenomenon with an incidence of about 1 in 1,000 pregnancies (4). However, because the usage rate of PET imaging in clinical practice has grown rapidly over the past few years, PET scanning of pregnant patients has also increased (5). For pregnant patients, the exposure of the embryo or fetus to ionizing radiation through standalone or hybrid nuclear medicine imaging examinations has long been a matter of concern because of the substantial radiosensitivity of the developing embryo/fetus $(6,7)$. In general terms, the pregnant woman has the same radiosensitivity as a nonpregnant woman and the radiation risks to the embryo/fetus depend on the gestational period at the time of exposure and the absorbed dose level (7). In the embryonic term (conception to the eighth week), ionizing radiation may cause death of the zygote or embryo. In the early fetal period (ninth week to the third month), the fetus is in its most sensitive stage to radiation, which may cause gross congenital malformations and mental retardation. The threshold dose was reported to be in the range of 100$200 \mathrm{mGy}(8)$. In the second and third trimesters (fourth month to the sixth month and seventh month to the ninth month), exposure to radiation may significantly affect the brain development of the fetus and results in average IQ loss ( $\sim 21-29$ IQ points per Gy) or severe mental retardation (9). The physiologic changes during pregnancy and the potential radiation risks to the embryo/fetus are important considerations and challenges for radiologists because they need to balance the benefits of performing a diagnostic imaging procedure to the mother with the risks to the mother and the embryo/fetus (10, 11). In this context, the maternal and fetal radiation dose estimates play an essential role in the assessment of radiation risks associated with diagnostic PET/CT imaging procedures during pregnancy.

Realistic computational models representing the human anatomy in connection with advanced Monte Carlo simulation tools have been extensively used for accurate calculation of the absorbed dose (12). In this work, we use new-generation pregnant female phantoms as input to Monte Carlo simulations to calculate the $\mathrm{S}$ values in different organs or tissues for 9 positron-emitting radionuclides as well as fetal/maternal absorbed doses and effective dose from 21 radiotracers for anthropomorphic pregnant models at different gestation periods. 


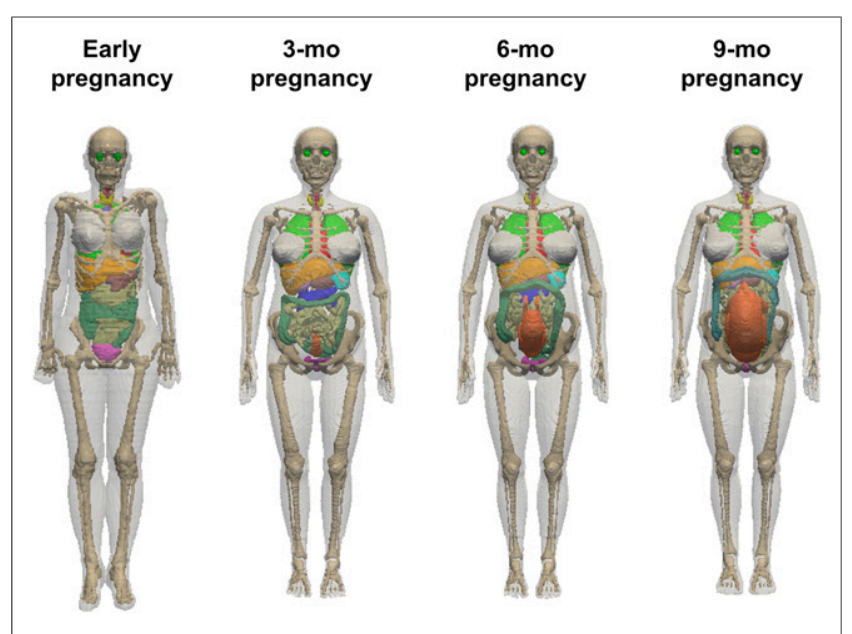

FIGURE 1. Three-dimensional visualization of computational pregnant female phantoms showing front views at early pregnancy, 3-mo pregnancy, 6-mo pregnancy, and 9-mo pregnancy. Uterine and placenta were set transparent in 3-, 6-, and 9-mo pregnant phantoms to exhibit fetus.

\section{MATERIALS AND METHODS}

The International Commission on Radiological Protection (ICRP) reference adult female phantom (13) and the Rensselaer Polytechnic Institute (RPI) pregnant female phantom series at 3-, 6-, and 9-mo (RPI-P3, RPI-P6, and RPI-P9) gestation (14) were used in this work to represent embryo/fetus and reference pregnant woman. The voxel-based RPI pregnant female models were generated from the original surface-represented models. A united voxel dimension of $3 \times 3 \times 3 \mathrm{~mm}$ and organ ID were set for all voxelized models to minimize the difference across the different models. In the ICRP reference adult female model, cortical bone, spongiosa, and bone marrow at different bone sites (e.g., skull, ribs and femurs) were combined as skeleton and the corresponding chemical composition considered as a mixture of cortical bone, trabecular bone, active marrow, and inactive marrow according to the mass of these suborgans in the reference adult female. Homogeneous organs (e.g., left and right lung) and some substructures of the same organ (e.g., the cortex, medulla, and pelvis of kidney) were merged as 1 individual region. This step was undertaken for the sake of convenience to enable the comparison of dosimetric results between the ICRP and RPI models. For dosimetry purposes, the development of the embryo/fetus can be divided into 2 terms (embryo and fetal). The term embryo (early pregnancy, from conception to eighth week) refers to the initial stages of growth and development up to the age at which most of the body organs are formed. The radiation doses to the embryo are considered to be similar to the dose to the uterus wall of the ICRP reference adult female because, in this term, the embryo weight is less than about $10 \mathrm{~g}$ and is closely associated with the tissues of the uterus (15). The fetal period, which comprises mostly the growth and maturation of organs, continues from the ninth week to birth and can be demarcated as 3 trimesters, which were represented by RPI-P3, RPI-P6, and RPI-P9 models. A total of 35 identified regions were considered in this work. Figure 1 shows 3-dimensional visualization of the front and side views of early pregnancy, the 3-, 6-, and 9-mo computational pregnant female phantoms used in this work. The MCNPX code (version 2.5.c) was used for radiation transport simulation (16). Uniformly distributed positron-emitting sources $\left({ }^{11} \mathrm{C},{ }^{13} \mathrm{~N},{ }^{15} \mathrm{O},{ }^{18} \mathrm{~F}\right.$, ${ }^{64} \mathrm{Cu},{ }^{68} \mathrm{Ga},{ }^{82} \mathrm{Rb},{ }^{86} \mathrm{Y}$, and ${ }^{124} \mathrm{I}$ ) were simulated in 35 source regions.

The PET radiotracers investigated in this work are ${ }^{11} \mathrm{C}$-acetate, ${ }^{11} \mathrm{C}$ - and ${ }^{18} \mathrm{~F}$-amino acids, ${ }^{11} \mathrm{C}$-methionine, ${ }^{11} \mathrm{C}$ and ${ }^{18} \mathrm{~F}$ brain receptor substances, ${ }^{11} \mathrm{C}$ (realistic maximum model), [methyl- ${ }^{11} \mathrm{C}$-thymidine, ${ }^{11} \mathrm{C}$-thymidine, ${ }^{11} \mathrm{C}$-1-(3,4-dimethoxyphenethyl)-4-(3-phenylprophyl)piperazine $\left({ }^{11} \mathrm{C}\right.$ SA4503), ${ }^{11} \mathrm{C}$-8-dicyclopropylmethyl-1-methyl-3-propylxanthine $\left({ }^{11} \mathrm{C}-\mathrm{MPDX}\right),{ }^{11} \mathrm{C}-(\mathrm{E})-8-(3,4,5-$ trimethoxystyryl)-1,3,7-trimethylxanthine
( $\left.{ }^{11} \mathrm{C}-\mathrm{TMSX}\right), \quad{ }^{4-11} \mathrm{C}-\mathrm{methylphenyl-1,4-diazabicyclo[3.2.2.]nonane-4-}$ carboxylate $\left({ }^{11} \mathrm{C}-\mathrm{CHIBA}-1001\right),{ }^{11} \mathrm{C}-4$ '-thiothymidine $\left({ }^{11} \mathrm{C}-4 \mathrm{DST}\right),{ }^{15} \mathrm{O}-$ water, ${ }^{18} \mathrm{~F}$-FDG, $6-{ }^{18} \mathrm{~F}$-fluoro-L-DOPA $\left({ }^{18} \mathrm{~F}-\mathrm{L}\right.$-DOPA $)$, 4-borono-2- ${ }^{18} \mathrm{~F}-$ fluoro-L-phenylalanine ( $\left.{ }^{18} \mathrm{~F}-\mathrm{FBPA}\right), 6-{ }^{18} \mathrm{~F}$-fluorodopamine $\left({ }^{18} \mathrm{~F}-\mathrm{FDOPA}\right)$, ${ }^{68} \mathrm{Ga}$-ethylenediaminetetraacetic acid $\left({ }^{68} \mathrm{Ga}\right.$-EDTA $)$, and ${ }^{68} \mathrm{Ga}$-DOTANOC. The biokinetic data of these radiotracers were obtained from the supplemental materials of ICRP publications and other published literature (17-19). Because the developing embryo/fetus takes up the injected compounds from maternal blood, and in accordance with Benveniste et al. (20) who suggested similar uptake values for fetal and maternal activity for ${ }^{18} \mathrm{~F}$-FDG, we assumed an equal average activity concentration in maternal and fetal tissues (21). The mean residence time (MRT) of a radiotracer $\mathrm{R}$ in source organs was calculated according to published MRT data, where maternal organs are classified in 2 types: organs of type I having a given $\mathrm{MRT}_{\mathrm{R}}^{\mathrm{Type}} \mathrm{I}$ and organs of type II consisting of all other organs. For organs of type I of the maternal body, the MRTs were calculated as:

$$
\mathrm{MRT}_{\text {maternal }}^{\text {Type I }}=\operatorname{MRT}_{\mathrm{R}}^{\mathrm{Type} \mathrm{I}} \times \frac{\text { Volume }_{\text {maternal }}^{\mathrm{TB}}}{\text { Volume }_{\text {maternal }}^{\mathrm{TB}}+\text { Volume }_{\text {fetal }}^{\mathrm{TB}}} . \quad \text { Eq. } 1
$$

For maternal organs of type II, the MRTs were calculated as:

$$
\begin{aligned}
\mathrm{MRT}_{\text {maternal }}^{\text {Type II }} & =\left(\mathrm{MRT}_{\mathrm{R}}^{\mathrm{Sum}}-\sum \mathrm{MRT}_{\mathrm{R}}^{\mathrm{Type} \mathrm{I}}\right) \\
& \times\left(\frac{\text { Volume }_{\text {maternal }}^{\mathrm{TB}}}{\text { Volume }_{\text {maternal }}^{\mathrm{TB}}+\text { Volume }_{\text {fetal }}^{\mathrm{TB}}}\right) \\
& \times\left(\frac{\text { Volume }_{\text {maternal }}^{\text {Type II }}}{\text { Volume }_{\text {maternal }}^{\mathrm{TB}}-\sum \text { Volume }_{\text {maternal }}^{\text {Type I }}}\right) .
\end{aligned}
$$

For fetal organs, the MRTs were estimated according to:

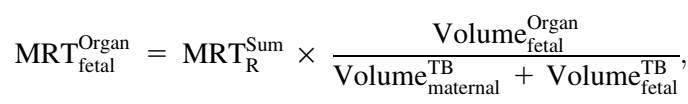

where $\mathrm{MRT}_{\mathrm{R}}^{\mathrm{Sum}}$ refers to the sum of MRT of radiotracer $\mathrm{R}$ in adult total body (TB).

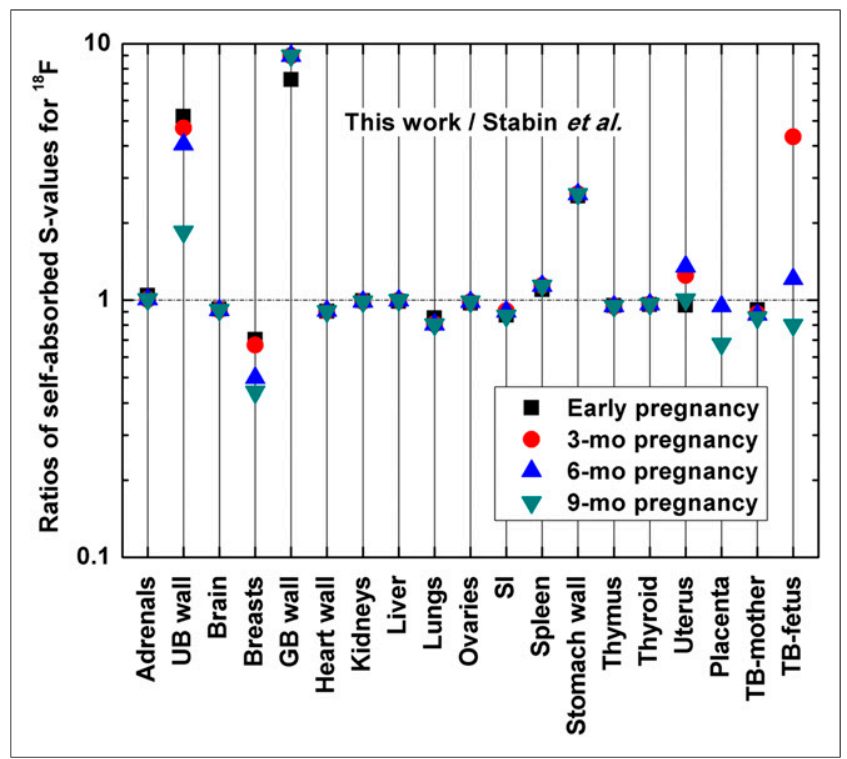

FIGURE 2. Comparison of self-absorbed $S$ values of ${ }^{18} \mathrm{~F}$ for common organs/tissues of pregnant women between this work and Stabin et al. (24). GB = gallbladder; $\mathrm{SI}=$ small intestine. 


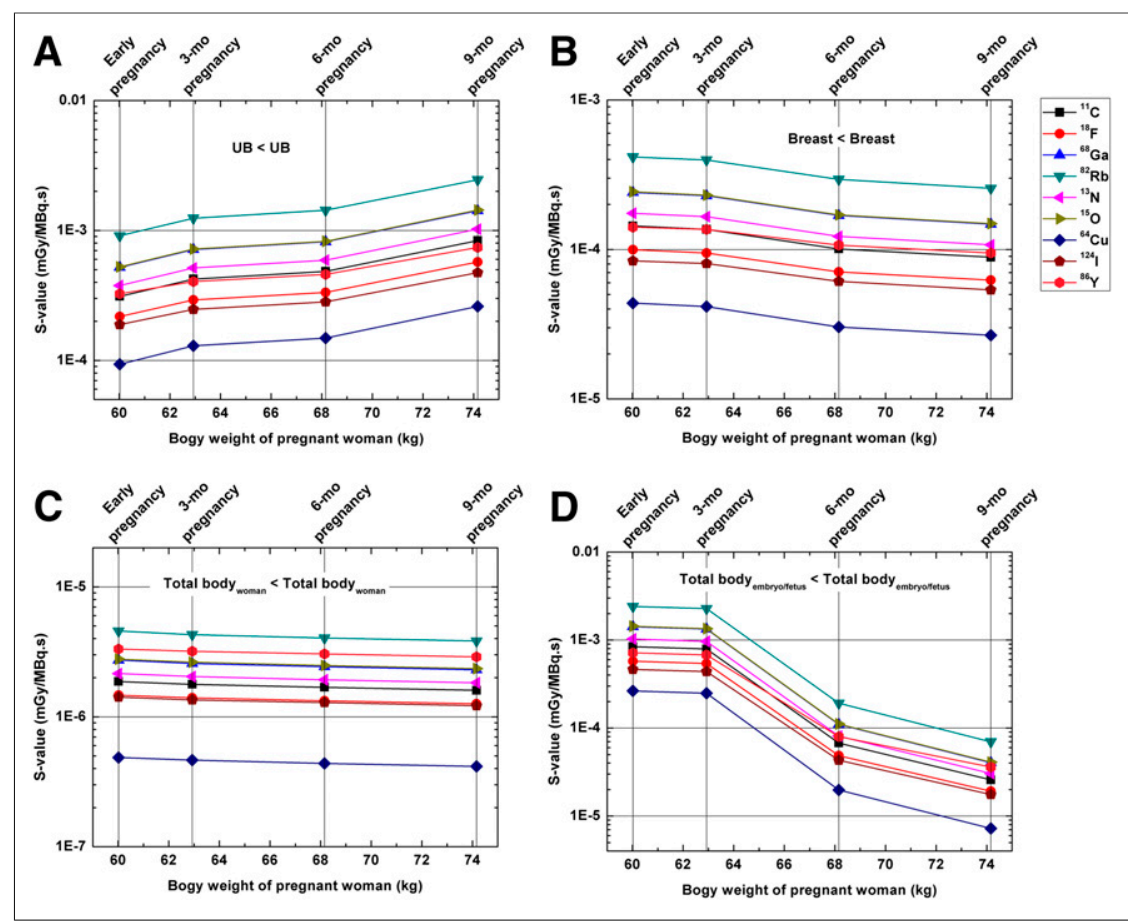

FIGURE 3. Self-absorbed $S$ values for UB (A), breast (B), and total body (C) of pregnant woman and embryo/fetus (D).

The MIRD formalism (22) and ICRP 103 recommendations (23) were used to calculate the $\mathrm{S}$ values of 9 positron-emitting radionuclides and radiation-absorbed dose and effective dose of 21 radiotracers in the considered pregnant female phantoms (supplemental material [available at http://jnm.snmjournals.org]).
RESULTS

$S$ Values for

\section{Positron-Emitting Radionuclides}

$\mathrm{S}$ values to 42 target regions from 9 positron-emitting radionuclides were calculated in the considered female phantoms and provided in the supplemental material. Figure 2 compares the self-absorbed $\mathrm{S}$ values of ${ }^{18} \mathrm{~F}$ between the results obtained in this work and those produced using the mathematic models developed by Stabin et al. (24) for representative target regions of the pregnant female. For solid organs of the pregnant female, there is good agreement of self-absorbed $S$ values between the voxel-based and mathematic models, whereas for hollow organs and regions changing significantly during pregnancy, such as the breast and urinary bladder (UB) wall, the ratios of self-absorbed $\mathrm{S}$ values between the 2 categories of models vary from 0.4 to 9.0 for ${ }^{18} \mathrm{~F}$. For the fetus, the ratios of the self-absorbed $S$ values between the voxel-based and the mathematic models vary between 0.8 and 4.6 , which may be attributed to the differences between the geometries and fetal mass of the 2 types of model. Figure 3 shows selfabsorbed $\mathrm{S}$ values for the UB, breast, and TB of the mother and fetus across different gestations. For maternal TB, and most considered organs, self-absorbed $\mathrm{S}$ values are almost constant at different gestation periods, whereas self-absorbed $S$ values for the $\mathrm{UB}$ and breast increase and decrease, respectively, when the maternal body weight increases because of the reduced UB mass and the expanded breast as shown in the supplemental material. For all positron-emitting radionuclides, the fetal $S$ values decrease while the fetal weight increases, and the average relative difference of fetal self-absorbed $\mathrm{S}$ values per kilogram difference in fetal weight $(\% / \mathrm{kg})$ between the 3-mo and the 9-mo pregnant female models is $-28.3 \% / \mathrm{kg}$.

\section{Absorbed Dose and Effective Dose}

Fetal and maternal absorbed doses of 42 target regions and effective dose to pregnant female models from 21 common positron-emitting radiotracers were evaluated and provided in the supplemental materials. Figure 4 shows the absorbed dose per unit administered activity of representative radiotracers to the kidneys, UB wall, TB of the mother, and embryo/fetus. For most considered maternal organs/ tissues and the TB of the mother, the absorbed dose from radiotracers decrease slightly with the progression of gestation, except the maternal UB wall where the absorbed dose obviously increases with the progression of gestation.
FIGURE 4. Absorbed dose per unit administered activity (mGy/MBq) of kidney (A), UB wall (B), and total body $(C)$ of embryo/fetus and pregnant model from selected radiotracers for different pregnant phantoms (D). 
TABLE 1

Effective Dose of Radiotracers in Pregnant Phantoms According to Tissue-Weighting Factors of ICRP Publication 103 (23)

\begin{tabular}{|c|c|c|c|c|}
\hline \multirow[b]{2}{*}{ Radiotracer } & \multirow[b]{2}{*}{ Early pregnancy (mSv/MBq) } & \multicolumn{3}{|c|}{ Gestation } \\
\hline & & $3 \mathrm{mo}(\mathrm{mSv} / \mathrm{MBq})$ & $6 \mathrm{mo}(\mathrm{mSv} / \mathrm{MBq})$ & $9 \mathrm{mo}(\mathrm{mSv} / \mathrm{MBq})$ \\
\hline${ }^{11} \mathrm{C}$-acetate & 4.11E-03 & 3.98E-03 & 3.88E-03 & $3.75 E-03$ \\
\hline${ }^{11} \mathrm{C}$-amino acids & 4.82E-03 & 4.61E-03 & 4.47E-03 & 4.40E-03 \\
\hline${ }^{11} \mathrm{C}$ brain receptor substances & 4.18E-03 & 4.17E-03 & 4.02E-03 & 4.11E-03 \\
\hline${ }^{11} \mathrm{C}-$ methionine & 5.82E-03 & 5.62E-03 & $5.68 E-03$ & 6.39E-03 \\
\hline${ }^{11} \mathrm{C}$ (realistic maximum model) & $5.88 E-03$ & 5.83E-03 & $6.01 E-03$ & 7.47E-03 \\
\hline [Methyl- $\left.{ }^{11} \mathrm{C}\right]$ thymidine & 5.30E-03 & $5.20 \mathrm{E}-03$ & $5.09 \mathrm{E}-03$ & 4.95E-03 \\
\hline${ }^{11} \mathrm{C}$-thymidine & 3.18E-03 & $3.18 \mathrm{E}-03$ & 3.01E-03 & $2.84 \mathrm{E}-03$ \\
\hline${ }^{11} \mathrm{C}-\mathrm{SA} 4503$ & 8.27E-03 & 7.90E-03 & 7.73E-03 & 7.57E-03 \\
\hline${ }^{11} \mathrm{C}-\mathrm{MPDX}$ & 4.29E-03 & 4.16E-03 & 4.04E-03 & 4.07E-03 \\
\hline${ }^{11} \mathrm{C}-\mathrm{TMSX}$ & 4.58E-03 & 4.44E-03 & 4.33E-03 & 4.33E-03 \\
\hline${ }^{11} \mathrm{C}-\mathrm{CHIBA}-1001$ & 8.58E-03 & $8.25 E-03$ & 8.07E-03 & $8.11 \mathrm{E}-03$ \\
\hline${ }^{11} \mathrm{C}-4 \mathrm{DST}$ & 5.13E-03 & 5.24E-03 & $5.25 \mathrm{E}-03$ & $6.15 \mathrm{E}-03$ \\
\hline${ }^{15} \mathrm{O}$-water & $1.05 E-03$ & $1.01 \mathrm{E}-03$ & 9.92E-04 & 9.64E-04 \\
\hline${ }^{18} \mathrm{~F}$-amino acids & 1.98E-02 & 1.88E-02 & 1.83E-02 & 1.82E-02 \\
\hline${ }^{18} \mathrm{~F}$ brain receptor substances & 2.64E-02 & $2.55 \mathrm{E}-02$ & $2.51 \mathrm{E}-02$ & $2.52 E-02$ \\
\hline${ }^{18} \mathrm{~F}-\mathrm{FDG}$ & $1.86 E-02$ & 1.73E-02 & $1.70 \mathrm{E}-02$ & 1.75E-02 \\
\hline${ }^{18} \mathrm{~F}-\mathrm{L}-\mathrm{DOPA}$ & $1.83 E-02$ & $1.73 E-02$ & $1.72 E-02$ & 1.91E-02 \\
\hline${ }^{18} \mathrm{~F}-\mathrm{FBPA}$ & 2.83E-02 & 3.06E-02 & $3.20 \mathrm{E}-02$ & 4.40E-02 \\
\hline${ }^{18} \mathrm{~F}-\mathrm{FDOPA}$ & 2.00E-02 & $1.88 \mathrm{E}-02$ & 1.88E-02 & 2.10E-02 \\
\hline${ }^{68} \mathrm{Ga}-\mathrm{EDTA}$ & $2.54 \mathrm{E}-02$ & 2.89E-02 & 3.04E-02 & 3.87E-02 \\
\hline${ }^{68} \mathrm{Ga}-\mathrm{DOTANOC}$ & 1.69E-02 & $1.68 \mathrm{E}-02$ & 1.67E-02 & 1.79E-02 \\
\hline
\end{tabular}

${ }^{11} \mathrm{C}-\mathrm{SA} 4503$ = ${ }^{11} \mathrm{C}-1$-(3,4-dimethoxyphenethyl)-4-(3-phenylprophyl)piperazine; ${ }^{11} \mathrm{C}-\mathrm{MPDX}={ }^{11} \mathrm{C}-8$-dicyclopropylmethyl-1-methyl-3propylxanthine; ${ }^{11} \mathrm{C}-\mathrm{TMSX}={ }^{11} \mathrm{C}-(\mathrm{E})-8-\left(3,4,5\right.$-trimethoxystyryl)-1,3,7-trimethylxanthine; ${ }^{11} \mathrm{C}-\mathrm{CHIBA}-1001=4{ }^{11} \mathrm{C}$-methylphenyl-1, 4-diazabicyclo[3.2.2.]nonane-4-carboxylate; ${ }^{11} \mathrm{C}-4 \mathrm{DST}={ }^{11} \mathrm{C}-4$ '-thiothymidine; ${ }^{18} \mathrm{~F}-\mathrm{L}-\mathrm{DOPA}=6$ - ${ }^{18} \mathrm{~F}-$ fluoro-L-DOPA; ${ }^{18} \mathrm{~F}-\mathrm{FBPA}=4$-borono$2-{ }^{18} \mathrm{~F}$-fluoro-L-phenylalanine; ${ }^{18} \mathrm{~F}$-FDOPA $=6$ - ${ }^{18} \mathrm{~F}$-fluorodopamine; ${ }^{68} \mathrm{Ga}-\mathrm{EDTA}={ }^{68} \mathrm{Ga}$-ethylenediaminetetraacetic acid.

The effective dose per unit administered activity of 21 radiotracers in the pregnant female models calculated using tissueweighting factors of the ICRP 103 are summarized in Table 1. For most investigated radiotracers, the corresponding maternal effective doses between early and 3-mo pregnancy models are very close, with an average absolute difference of $3.9 \%$ between the 2 models. This difference can be attributed to individual differences between the ICRP reference phantom and RPI phantoms.
Among the considered radiotracers and pregnant female models at different gestations, ${ }^{18} \mathrm{~F}$-FBPA produces the highest effective dose, ranging from $2.83 \mathrm{E}-02$ to $4.40 \mathrm{E}-02 \mathrm{mSv} / \mathrm{MBq}$, whereas ${ }^{15} \mathrm{O}-$ water produces the lowest effective dose, ranging from $9.64 \mathrm{E}-04$ to $1.05 \mathrm{E}-03 \mathrm{mSv} / \mathrm{MBq}$. Figure 5 shows the ratios of the effective dose of pregnant women models at 3-, 6-, and 9-mo gestations to the early pregnant model. For most studied radiotracers, the maternal effective dose changes slightly from early to end of preg-

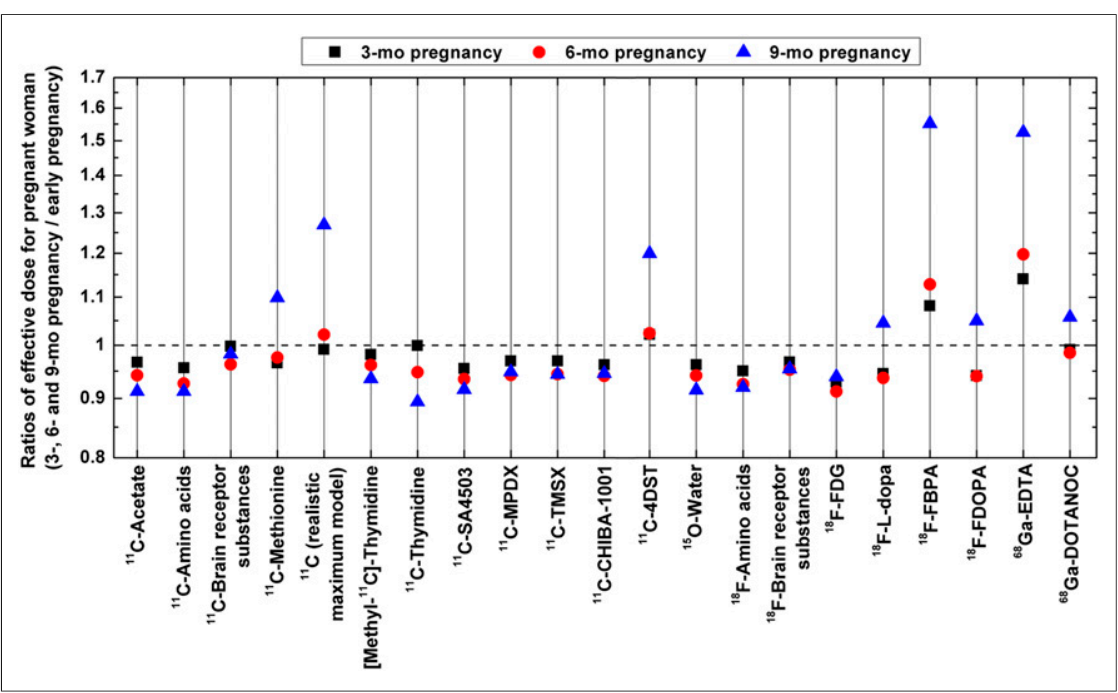

FIGURE 5. Ratios of effective dose of pregnant model from 3-, 6-, and 9-mo gestations to early pregnancy for 21 studied radiotracers. nancy, whereas the ratios of effective doses between models vary from 0.91 to 1.05 . However, for ${ }^{11} \mathrm{C}$ (realistic maximum model), ${ }^{11} \mathrm{C}-4 \mathrm{DST},{ }^{18} \mathrm{~F}-\mathrm{FBPA}$, and ${ }^{68} \mathrm{Ga}-$ EDTA, the effective doses in the 9-mo pregnant female model are about $20 \%-$ $55 \%$ larger than those of the early pregnant female model.

The embryonic/fetal absorbed dose decreases significantly with the growth of the embryo/fetus (Fig. 4). Table 2 lists the absorbed dose estimates to the embryo/ fetus per unit activity of 21 considered positron-emitting radiotracers administered to the mother. The highest embryonic/fetal absorbed dose was achieved for ${ }^{18} \mathrm{~F}-\mathrm{FDOPA}$, namely $5.91 \mathrm{E}-02,3.79 \mathrm{E}-02,2.00 \mathrm{E}-02$, and $1.68 \mathrm{E}-02 \mathrm{mGy} / \mathrm{MBq}$ for early pregnancy and 3-, 6-, and 9-mo gestations, respectively. The lowest embryonic/fetal absorbed dose was observed for ${ }^{15} \mathrm{O}$-water. 
TABLE 2

Absorbed Dose Estimates to Embryo/Fetus Per Unit Activity of Different Radiotracers Administered to Pregnant Mother

\begin{tabular}{|c|c|c|c|c|}
\hline \multirow[b]{2}{*}{ Radiotracer } & \multirow[b]{2}{*}{ Early pregnancy (mGy/MBq) } & \multicolumn{3}{|c|}{ Gestation } \\
\hline & & 3 mo (mGy/MBq) & 6 mo (mGy/MBq) & 9 mo (mGy/MBq) \\
\hline${ }^{11} \mathrm{C}$-acetate & $1.54 \mathrm{E}-03$ & $2.12 E-03$ & $2.05 E-03$ & 1.94E-03 \\
\hline${ }^{11} \mathrm{C}$-amino acids & 4.71E-03 & $4.25 E-03$ & 3.51E-03 & $3.19 \mathrm{E}-03$ \\
\hline${ }^{11} \mathrm{C}$ brain receptor substances & $6.69 E-03$ & $5.11 \mathrm{E}-03$ & 3.61E-03 & $3.21 \mathrm{E}-03$ \\
\hline${ }^{11} \mathrm{C}$-methionine & 1.14E-02 & $7.59 \mathrm{E}-03$ & 4.01E-03 & $3.40 \mathrm{E}-03$ \\
\hline${ }^{11} \mathrm{C}$ (realistic maximum model) & 2.06E-02 & $1.22 E-02$ & $5.38 \mathrm{E}-03$ & $4.31 E-03$ \\
\hline [Methyl- $\left.{ }^{11} \mathrm{C}\right]$ thymidine & 2.07E-03 & $2.81 \mathrm{E}-03$ & $2.75 \mathrm{E}-03$ & 2.63E-03 \\
\hline${ }^{11} \mathrm{C}$-thymidine & 2.84E-03 & $2.74 \mathrm{E}-03$ & 2.50E-03 & 2.31E-03 \\
\hline${ }^{11} \mathrm{C}-\mathrm{SA} 4503$ & 2.63E-03 & $3.26 \mathrm{E}-03$ & 3.03E-03 & 2.84E-03 \\
\hline${ }^{11} \mathrm{C}-\mathrm{MPDX}$ & $3.77 E-03$ & $3.72 \mathrm{E}-03$ & 3.29E-03 & 3.04E-03 \\
\hline${ }^{11} \mathrm{C}-\mathrm{TMSX}$ & 3.67E-03 & 3.67E-03 & 3.30E-03 & $3.05 E-03$ \\
\hline${ }^{11} \mathrm{C}-\mathrm{CHIBA}-1001$ & 3.34E-03 & 4.01E-03 & 3.34E-03 & 3.09E-03 \\
\hline${ }^{11} \mathrm{C}-4 \mathrm{DST}$ & $5.23 E-03$ & 4.33E-03 & $3.46 E-03$ & $3.15 E-03$ \\
\hline${ }^{15} \mathrm{O}$-water & $4.54 \mathrm{E}-04$ & 4.92E-04 & $4.50 E-04$ & $4.15 E-04$ \\
\hline${ }^{18} \mathrm{~F}$ amino acids & 2.34E-02 & 1.97E-02 & $1.50 \mathrm{E}-02$ & 1.36E-02 \\
\hline${ }^{18} \mathrm{~F}$ brain receptor substances & 2.67E-02 & $2.12 E-02$ & $1.51 \mathrm{E}-02$ & 1.37E-02 \\
\hline${ }^{18} \mathrm{~F}-\mathrm{FDG}$ & 3.05E-02 & 2.27E-02 & $1.50 \mathrm{E}-02$ & 1.33E-02 \\
\hline${ }^{18} \mathrm{~F}-\mathrm{L}-\mathrm{DOPA}$ & 5.31E-02 & $3.36 \mathrm{E}-02$ & 1.70E-02 & 1.42E-02 \\
\hline${ }^{18} \mathrm{~F}-\mathrm{FBPA}$ & 4.56E-02 & 2.98E-02 & 1.76E-02 & 1.52E-02 \\
\hline${ }^{18} \mathrm{~F}-\mathrm{FDOPA}$ & 5.91E-02 & 3.79E-02 & 2.00E-02 & 1.68E-02 \\
\hline${ }^{68} \mathrm{Ga}-\mathrm{EDTA}$ & 4.91E-02 & 3.13E-02 & 1.77E-02 & $1.50 \mathrm{E}-02$ \\
\hline${ }^{68} \mathrm{Ga}-\mathrm{DOTANOC}$ & 1.84E-02 & 1.52E-02 & 1.18E-02 & 1.06E-02 \\
\hline
\end{tabular}

${ }^{11} \mathrm{C}-\mathrm{SA} 4503$ = ${ }^{11} \mathrm{C}-1$-(3,4-dimethoxyphenethyl)-4-(3-phenylprophyl)piperazine; ${ }^{11} \mathrm{C}-\mathrm{MPDX}={ }^{11} \mathrm{C}-8$-dicyclopropylmethyl-1-methyl-3propylxanthine; ${ }^{11} \mathrm{C}-\mathrm{TMSX}={ }^{11} \mathrm{C}-(\mathrm{E})-8-\left(3,4,5\right.$-trimethoxystyryl)-1,3,7-trimethylxanthine; ${ }^{11} \mathrm{C}-\mathrm{CHIBA}-1001=4{ }^{11} \mathrm{C}$-methylphenyl-1, 4-diazabicyclo[3.2.2.]nonane-4-carboxylate; ${ }^{11} \mathrm{C}-4 \mathrm{DST}={ }^{11} \mathrm{C}-4$ '-thiothymidine; ${ }^{18} \mathrm{~F}-\mathrm{L}-\mathrm{DOPA}=6$ - ${ }^{18} \mathrm{~F}-$ fluoro-L-DOPA; ${ }^{18} \mathrm{~F}-\mathrm{FBPA}=4$-borono2-18 F-fluoro-L-phenylalanine; ${ }^{18} \mathrm{~F}-\mathrm{FDOPA}=6-{ }^{18} \mathrm{~F}$-fluorodopamine; ${ }^{68} \mathrm{Ga}-\mathrm{EDTA}={ }^{68} \mathrm{Ga}$-ethylenediaminetetraacetic acid.

Table 3 compares the estimated fetal absorbed doses for ${ }^{18} \mathrm{~F}-$ FDG in pregnant women between this work and results reported in the literature. Zanotti-Fregonara et al. (25) reported the highest fetal absorbed dose for ${ }^{18} \mathrm{~F}-\mathrm{FDG}$ at early pregnancy because of the much higher ${ }^{18} \mathrm{~F}$-FDG uptake in fetal tissues and smaller fetal weight in the considered case. The estimated absorbed doses for ${ }^{18} \mathrm{~F}-\mathrm{FDG}$ to the embryo/fetus in this work are $3.05 \mathrm{E}-02,2.27 \mathrm{E}-02,1.50 \mathrm{E}-02$, and $1.33 \mathrm{E}-02 \mathrm{mGy} /$ $\mathrm{MBq}$ at early pregnancy and 3-, 6-, and 9-mo gestations, respectively. The embryonic/fetal absorbed doses obtained in this work are higher than those reported by Stabin et al. (21) at early pregnancy and 3-mo gestation, but lower than corresponding values at 6- and 9-mo gestations. This difference is mainly caused by the intrinsic geometric differences between the com- putational pregnant female phantoms and weighting factors used in these studies.

Figure 6 shows the absorbed dose to different fetal tissues in the 9 -mo pregnant female model from representative radiotracers. For most positron-emitting labeled radiotracers, the fetal brain receives the highest radiation dose, compared with soft tissue or the skeleton. The estimated absorbed doses in the fetal brain are about 1.03-2.00 times larger than those of other fetal soft tissues.

\section{Fetal Dose of Radiotracers for PET Imaging of Pheochromocytoma}

Pheochromocytoma is an uncommon catecholamine-producing endocrine tumor in the adrenal medulla and is associated with sustained or paroxysmal episodes of hypertension, pallor, headaches, and

TABLE 3

Comparison of Fetal Absorbed Dose for ${ }^{18} \mathrm{~F}-\mathrm{FDG}$ in Pregnant Women at Different Periods of Gestation

\begin{tabular}{|c|c|c|c|c|}
\hline \multirow[b]{2}{*}{ Radiotracer: ${ }^{18} \mathrm{~F}-\mathrm{FDG}$} & \multirow[b]{2}{*}{ Early pregnancy (mGy/MBq) } & \multicolumn{3}{|c|}{ Gestation } \\
\hline & & 3-mo (mGy/MBq) & 6-mo (mGy/MBq) & 9-mo (mGy/MBq) \\
\hline Russell et al. (6) & $2.70 \mathrm{E}-02$ & $1.70 \mathrm{E}-02$ & $9.40 \mathrm{E}-03$ & $8.10 \mathrm{E}-03$ \\
\hline Stabin (21) & $2.20 \mathrm{E}-02$ & $2.20 \mathrm{E}-02$ & $1.70 \mathrm{E}-02$ & $1.70 \mathrm{E}-02$ \\
\hline Zanotti-Fregonara et al. (25) & 4.00E-02 (10-wk) & - & - & - \\
\hline Zanotti-Fregonara et al. (31) & 3.30E-02 (8-wk) & - & - & - \\
\hline Takalkar et al. (32) & $1.55 \mathrm{E}-02$ (6-wk) & 7.16E-03 (18-wk) & $6.16 \mathrm{E}-03^{*}$ & $1.06 \mathrm{E}-02(30-w k)$ \\
\hline This work & $3.05 \mathrm{E}-02$ & 2.27E-02 & $1.50 \mathrm{E}-02$ & $1.33 \mathrm{E}-02$ \\
\hline
\end{tabular}

${ }^{*}$ Average of fetal absorbed dose from 23- and 25-wk pregnant women. 


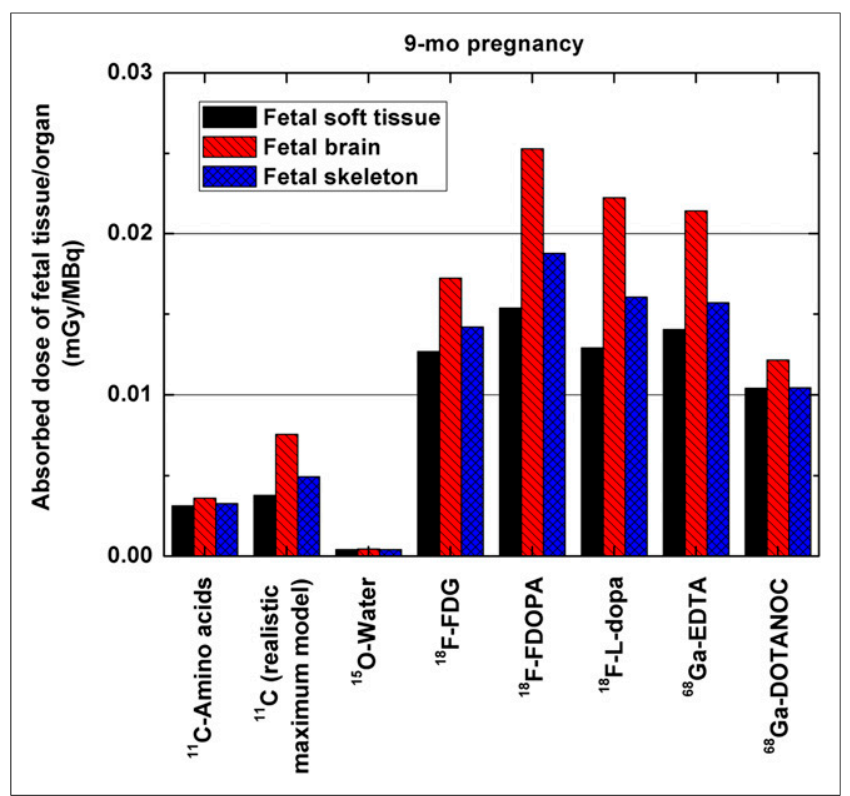

FIGURE 6. Absorbed dose per unit administered activity (mGy/MBq) of 3 fetal tissues/organs from selected radiotracers for 9-mo pregnant model.

palpitations (26). An unrecognized pheochromocytoma is particularly dangerous during pregnancy, because a potentially fatal hypertensive crisis can be precipitated by anesthesia, vaginal delivery, abdominal palpation, uterine contraction, and even vigorous fetal movements. Pheochromocytoma may cause a high rate of maternal and fetal mortality, which in some surveys reaches $40 \%-50 \%$ (27). Few radiotracers were suggested for PET imaging of pheochromocytoma, including ${ }^{18} \mathrm{~F}-\mathrm{FDG},{ }^{18} \mathrm{~F}$-FDOPA, ${ }^{11} \mathrm{C}$-labeled metahydroxephedrine, and ${ }^{68} \mathrm{Ga}$-DOTANOC (28). Figure 7 compares the fetal absorbed dose and maternal effective dose from ${ }^{18} \mathrm{~F}$-FDG, ${ }^{18} \mathrm{~F}$-FDOPA, ${ }^{11} \mathrm{C}$-labeled radiotracers, and ${ }^{68} \mathrm{Ga}$-DOTANOC at different gestations. The ${ }^{11} \mathrm{C}$ maximum model was used to estimate the radiation dose of ${ }^{11} \mathrm{C}$-labeled metahydroxephedrine. It can be seen that ${ }^{18} \mathrm{~F}$-FDOPA and ${ }^{11} \mathrm{C}$-labeled radiotracers produce the largest and smallest fetal and maternal effective dose, respectively. The fetal effective dose of ${ }^{18} \mathrm{~F}$-FDG is about $25.8 \%-66.2 \%$ higher than the effective dose of ${ }^{68} \mathrm{Ga}$-DOTANOC while the maternal effective doses of the 2 radiotracers are close.

\section{DISCUSSION}

PET provides important information about disease and pathology, often playing a critical role in patient management. However, when PET examinations are performed on patient populations with higher radiation risk, such as pregnant women, the balance between the benefits of imaging and the risks from radiation exposure to the unborn fetus becomes a challenge for physicists and nuclear medicine physicians. Accurate fetal and maternal absorbed dose estimates for common PET radiotracers is highly desired for the evaluation of risks and benefits of diagnostic imaging procedures in pregnant patients.

In this work, we estimated the $\mathrm{S}$ values of 9 positron-emitting radionuclides in new-generation computational pregnant female phantoms and calculated the fetal and maternal absorbed dose and effective dose from 21 positron-emitting labeled radiotracers based on the latest dosimetric data available. The effect of model type and maternal physical changes during gestation on resulting $S$ values from various radionuclides to the pregnant population was studied. A large difference between $\mathrm{S}$ values was observed for hollow organs when using the MIRD-type mathematic models and the voxel-based models (29, 30 ). The $\mathrm{S}$ values of voxel-based models used in this work would be more accurate than those of mathematic models because the former preserves more anatomic details of the human body. In general, the self-absorbed $\mathrm{S}$ values for most organs do not change during pregnancy whereas the $S$ values for the maternal UB and the fetal body increase and decrease, respectively, with the progress of gestation. Ionizing radiation may result in a significantly higher absorbed dose in the embryo or fetus at early pregnancy. Because fetal tissues have higher sensitivity to ionizing radiation in the organogenic period from the end of the embryo term to the beginning of the first trimester, this results in especially higher radiation risks.

Similar to $\mathrm{S}$ values, the maternal absorbed doses to most organs for the considered radiotracers are constant during various gestation periods whereas the absorbed dose for the UB wall increases with the progress of pregnancy. Recent literature seems to indicate that the radiation risks to pregnant patients from radiotracers are similar to those of normal adult females. In this work, maternal effective doses are less influenced by the anatomic changes of the female body in pregnancy for most investigated radiotracers. However, for some radiotracers that present a high activity concentration in the $\mathrm{UB}$, such as ${ }^{11} \mathrm{C}$ (realistic maximum model), ${ }^{11} \mathrm{C}-4 \mathrm{DST},{ }^{18} \mathrm{~F}-\mathrm{FBPA}$, and ${ }^{68} \mathrm{Ga}$-EDTA, the maternal effective dose in the third trimester
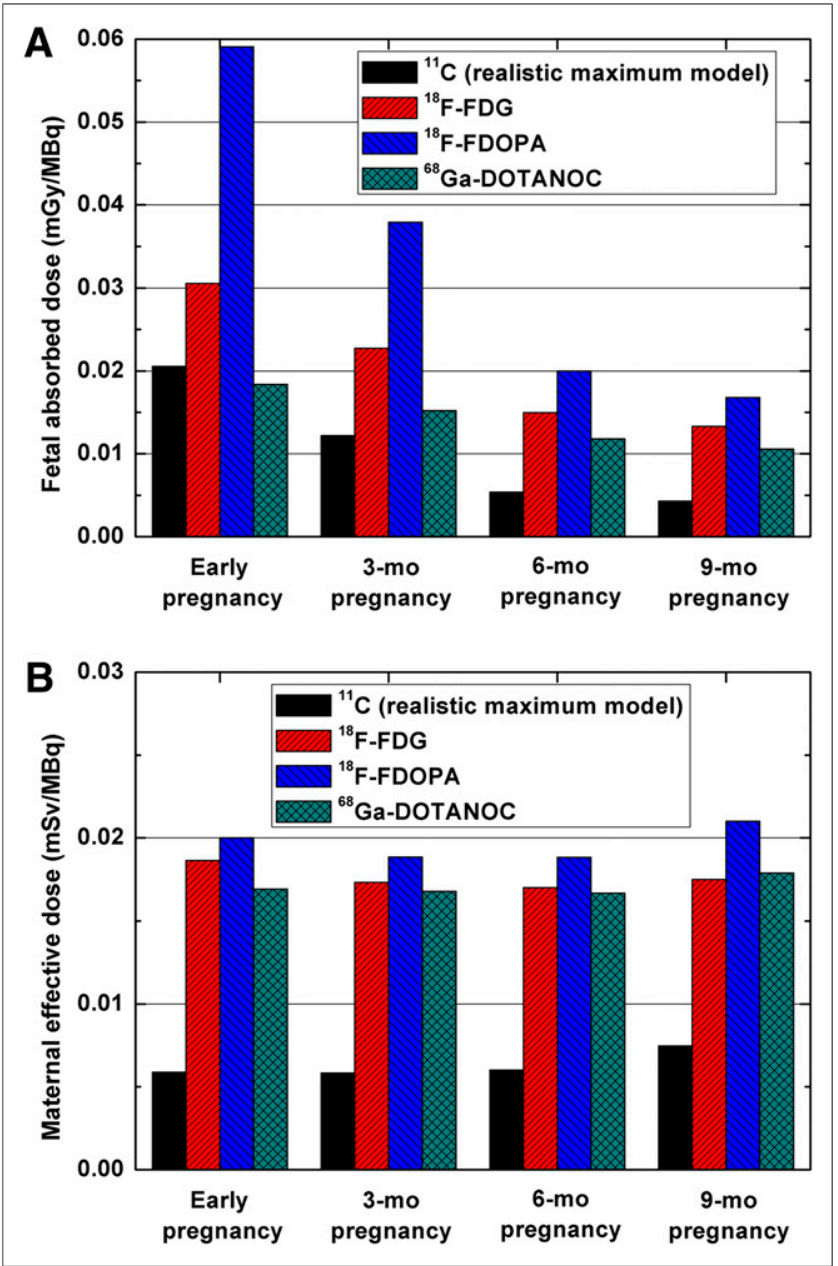

FIGURE 7. Fetal absorbed dose (A) and maternal effective dose (B) of ${ }^{11} \mathrm{C}$ (realistic maximum model), ${ }^{18} \mathrm{~F}-\mathrm{FDG},{ }^{18} \mathrm{~F}-\mathrm{FDOPA}$, and ${ }^{68} \mathrm{Ga}-\mathrm{DOTANOC}$ for different pregnant phantoms. 
would be about $20 \%-55 \%$ larger than that in early pregnancy. This change of effective dose should be considered in radiation risk analysis for pregnant patients undergoing diagnostic imaging procedures involving the use of these radiotracers.

The estimated fetal absorbed dose from common positron-emitting radiotracers presents an inverse correlation with the fetal weight. The relative difference in fetal absorbed dose per kilogram difference in fetal weight $(\% / \mathrm{kg})$ from considered radiotracers between the 3-mo pregnant female model and the 9-mo pregnant female model vary between $-1.84 \%$ and $-18.98 \% / \mathrm{kg}$. The fetal dose of ${ }^{18} \mathrm{~F}-\mathrm{FDG}$ estimated in this work differs slightly from the values reported for mathematic models at different gestation periods $(6,21)$. These differences are mainly caused by the different fetal mass (e.g., 85 vs. $458 \mathrm{~g}$ for the 3-mo pregnant female models) and the different representations of the anatomic structures (nonuniform rational B-splines-based surface representations vs. simple equation-based mathematic functions) between the new (more realistic) computational models and the old stylized models. For fetal dose at early pregnancy, the deviation between values reported in this work and Zanotti-Fregonara et al. (25) can be attributed to the different embryonic/fetal weight and activity concentration of ${ }^{18} \mathrm{~F}-\mathrm{FDG}$ in the embryo/fetus.

The absorbed doses from all investigated radiotracers are nonuniformly distributed in the fetal body. The fetal brain receives a significantly higher absorbed dose than fetal soft tissue and skeleton for some radiotracers. Because in the occiput anterior position of the fetus the fetal brain is close to maternal UB, this would result in noticeably high cross-absorbed radiation dose in the fetal brain when the radiotracer has a large number of disintegrations (residence time) in the maternal UB. The partial irradiation and high absorbed dose in the fetal brain may be related to the average IQ loss or mental retardation after birth.

The comparison of fetal absorbed dose and maternal effective dose for ${ }^{18} \mathrm{~F}$-FDG, ${ }^{18} \mathrm{~F}$-FDOPA, ${ }^{11} \mathrm{C}$-labeled radiotracers, and ${ }^{68} \mathrm{Ga}-$ DOTANOC, which are the tracers of choice for imaging of pheochromocytoma, shows the importance of a priori knowledge of dosimetric estimates during the selection of radiotracers for pregnant patients. The short half-life of ${ }^{11} \mathrm{C}$-labeled radiotracers limits its clinical application. The maternal effective dose from ${ }^{68} \mathrm{Ga}-$ DOTANOC approximates that of ${ }^{18} \mathrm{~F}-\mathrm{FDG}$ while the fetal dose of ${ }^{68} \mathrm{Ga}$-DOTANOC is lower than that of ${ }^{18} \mathrm{~F}-\mathrm{FDG}$ and ${ }^{18} \mathrm{~F}-$ FDOPA. In this context, ${ }^{68} \mathrm{Ga}$-DOTANOC has favorable dosimetric characteristics and presents a good clinical potential for pheochromocytoma imaging of pregnant patients.

The generated radiation dosimetry database is the first systematic estimate of fetal dose from positron-emitting labeled radiotracers, and the calculated $\mathrm{S}$ values can be used for the assessment of radiation dose to the embryos/fetus and pregnant females undergoing PET imaging procedures at different gestations from new positron-emitter labeled radiotracers. This work may further advance the understanding of the uncertainties involved in internal radiation dosimetry calculations.

\section{CONCLUSION}

A systematic study was conducted to evaluate the dose delivered to the fetus and gravida from common positron-emitting radionuclides and radiotracers using the latest-generation computational anthropomorphic pregnant female phantoms, updated tissue-weighting factors, and biodistribution data. We also investigated the impact of different model types and gestation periods on the resulting organ $\mathrm{S}$ values, maternal effective dose, and fetal absorbed dose.
The latest-generation computational models provide more accurate estimates of $\mathrm{S}$ values of hollow organs and the growing fetus. For some radiotracers (such as ${ }^{18} \mathrm{~F}$-FBPA and ${ }^{68} \mathrm{Ga}-\mathrm{EDTA}$ ), the anatomic changes of the maternal body would significantly increase the effective dose to the pregnant woman, which should be considered in nuclear imaging of pregnant patients. The absorbed radiation dose presents a nonuniform distribution in the fetus because the fetal brain would receive a noticeably higher absorbed dose than other fetal tissues. The calculation of the fetal dose depends on both the fetal weight and the biokinetic data of radiotracers. Consequently, human-based biokinetic studies are often desired for PET molecular imaging probes. The produced $\mathrm{S}$ values for positron-emitting radionuclides can be exploited to assess the radiation dose delivered by various radiotracers to pregnant patients and the embryo/fetus at different gestations in clinical and research settings. The generated dosimetric database can be used for the evaluation of radiation risks to pregnant woman and the unborn embryo/fetus in clinical PET imaging procedures.

\section{DISCLOSURE}

The costs of publication of this article were defrayed in part by the payment of page charges. Therefore, and solely to indicate this fact, this article is hereby marked "advertisement" in accordance with 18 USC section 1734 . This work was supported by Geneva Cancer League and Geneva University Hospital under grant PRD 11-II-1 Geneva. No other potential conflict of interest relevant to this article was reported.

\section{ACKNOWLEDGMENT}

We thank Prof. George Xu (Rensselaer Polytechnic Institute) for providing the pregnant computational models.

\section{REFERENCES}

1. Siegel R, Ma J, Zou Z, Jemal A. Cancer statistics, 2014. CA Cancer J Clin. 2014;64:9-29.

2. Gambhir SS. Molecular imaging of cancer with positron emission tomography. Nat Rev Cancer. 2002;2:683-693.

3. Czernin J, Allen-Auerbach M, Schelbert HR. Improvements in cancer staging with PET/CT: literature-based evidence as of September 2006. J Nucl Med. 2007;48:78S-88S.

4. Voulgaris E, Pentheroudakis G, Pavlidis N. Cancer and pregnancy: a comprehensive review. Surg Oncol. 2011;20:e175-e185.

5. Lazarus E, Debenedectis C, North D, Spencer PK, Mayo-Smith WW. Utilization of imaging in pregnant patients: 10-year review of 5270 examinations in 3285 patients-1997-2006. Radiology. 2009;251:517-524.

6. Russell JR, Stabin MG, Sparks RB, Watson E. Radiation absorbed dose to the embryo/fetus from radiopharmaceuticals. Health Phys. 1997;73:756769.

7. Stovall M, Blackwell CR, Cundiff J, et al. Fetal dose from radiotherapy with photon beams: report of AAPM Radiation Therapy Committee Task Group No. 36. Med Phys. 1995;22:63-82.

8. Kusama T, Ota K. Radiological protection for diagnostic examination of pregnant women. Congenit Anom (Kyoto). 2002;42:10-14.

9. De Santis M, Di Gianantonio E, Straface G, et al. Ionizing radiations in pregnancy and teratogenesis: a review of literature. Reprod Toxicol. 2005;20:323-329.

10. Bural GG, Laymon CM, Mountz JM. Nuclear imaging of a pregnant patient: should we perform nuclear medicine procedures during pregnancy? Mol Imaging Radionucl Ther. 2012;21:1-5.

11. Doyle S, Messiou C, Rutherford JM, Dineen RA. Cancer presenting during pregnancy: radiological perspectives. Clin Radiol. 2009;64:857-871.

12. Zaidi H, Xu XG. Computational anthropomorphic models of the human anatomy: the path to realistic Monte Carlo modeling in medical imaging. Annu Rev Biomed Eng. 2007;9:471-500.

13. ICRP publication 103: the 2007 recommendations of the International Commission on Radiological Protection. Ann ICRP. 2007;37:1-332. 
14. Xu XG, Taranenko V, Zhang J, Shi C. A boundary-representation method for designing whole-body radiation dosimetry models: pregnant females at the ends of three gestational periods-RPI-P3, -P6 and -P9. Phys Med Biol. 2007;52:7023-7044.

15. ICRP publication 88: doses to the embryo and fetus from intakes of radionuclides by the mother. Ann ICRP. 2001;31:19-515.

16. Pelowitz DB. MCNPX User's Manual Version 2.5.0. Report LA-CP-05-0369. Los Alamos, NM: Los Alamos National Laboratory; 2005.

17. Sakata M, Oda K, Toyohara J, Ishii K, Nariai T, Ishiwata K. Direct comparison of radiation dosimetry of six PET tracers using human whole-body imaging and murine biodistribution studies. Ann Nucl Med. 2013;27:285-296.

18. Eskola O, Gronroos TJ, Naum A, et al. Novel electrophilic synthesis of $6-\left[{ }^{18} \mathrm{~F}\right]$ fluorodopamine and comprehensive biological evaluation. Eur J Nucl Med Mol Imaging. 2012;39:800-810.

19. Pettinato C, Sarnelli A, Di Donna M, et al. ${ }^{68} \mathrm{Ga}$-DOTANOC: biodistribution and dosimetry in patients affected by neuroendocrine tumors. Eur J Nucl Med Mol Imaging. 2008;35:72-79.

20. Benveniste H, Fowler JS, Rooney WD, et al. Maternal-fetal in vivo imaging: a combined PET and MRI study. J Nucl Med. 2003;44:1522-1530.

21. Stabin MG. Proposed addendum to previously published fetal dose estimate tables for ${ }^{18}$ F-FDG. J Nucl Med. 2004;45:634-635.

22. Bolch WE, Eckerman KF, Sgouros G, Thomas SR. MIRD pamphlet no. 21: a generalized schema for radiopharmaceutical dosimetry-standardization of nomenclature. J Nucl Med. 2009;50:477-484.
23. ICRP publication 103: the 2007 recommendations of the International Commission on Radiological Protection. Ann ICRP. 2007;37:1-332.

24. Stabin MG, Siegel JA. Physical models and dose factors for use in internal dose assessment. Health Phys. 2003;85:294-310.

25. Zanotti-Fregonara P, Jan S, Taieb D, et al. Absorbed ${ }^{18} \mathrm{~F}-\mathrm{FDG}$ dose to the fetus during early pregnancy. $J$ Nucl Med. 2010;51:803-805.

26. Kalra JK, Jain V, Bagga R, et al. Pheochromocytoma associated with pregnancy. J Obstet Gynaecol Res. 2003;29:305-308.

27. Lenders JW. Pheochromocytoma and pregnancy: a deceptive connection. Eur J Endocrinol. 2012;166:143-150.

28. Taïeb D, Timmers HJ, Hindie E, et al. EANM 2012 guidelines for radionuclide imaging of phaeochromocytoma and paraganglioma. Eur J Nucl Med Mol Imaging. 2012;39:1977-1995.

29. Xie T, Zaidi H. Assessment of S-values in stylized and voxel-based rat models for positron-emitting radionuclides. Mol Imaging Biol. 2013;15:542-551.

30. Xie T, Zhang G, Li Y, Liu Q. Comparison of absorbed fractions of electrons and photons using three kinds of computational phantoms of rat. Appl Phys Lett. 2010;97:33702-33704.

31. Zanotti-Fregonara $\mathrm{P}$, Jan $\mathrm{S}$, Champion $\mathrm{C}$, et al. In vivo quantification of ${ }^{18} \mathrm{~F}-$ FDG uptake in human placenta during early pregnancy. Health Phys. 2009;97: 82-85.

32. Takalkar AM, Khandelwal A, Lokitz S, Lilien DL, Stabin MG. ${ }^{18}$ F-FDG PET in pregnancy and fetal radiation dose estimates. J Nucl Med. 2011;52:1035-1040. 